Meta

Journal des tradlucteurs

Translators' Journal

\title{
Un prix de traduction unique en son genre
}

\section{Yves Gambier}

Volume 37, numéro 3, septembre 1992

URI : https://id.erudit.org/iderudit/002803ar

DOI : https://doi.org/10.7202/002803ar

Aller au sommaire du numéro

Éditeur(s)

Les Presses de l'Université de Montréal

ISSN

0026-0452 (imprimé)

1492-1421 (numérique)

Découvrir la revue

Citer cette note

Gambier, Y. (1992). Un prix de traduction unique en son genre. Meta, 37(3),

573-573. https://doi.org/10.7202/002803ar d'utilisation que vous pouvez consulter en ligne.

https://apropos.erudit.org/fr/usagers/politique-dutilisation/ 
expressing the different rhythms within the act of writing);

- a theory that would lay great emphasis on the language produced in the interstices of thought, that is to say in silences.

Thus, in our new theory the translator needs not dwell on the special linguistic nature of the poetic language; he ought to go farther, onto the "statis" of poetic language, onto the signs produced by it. The post-literature will certainly be a word-image literature. Then, the work of the translator will be the transposition of signs from one culture into another, from one sensitivity into another. He will need to call for a semiotical theory of translation.

\section{Martha Pulido-Correa}

Paris, France

\section{UN PRIX DE TRADUCTION UNIQUE EN SON GENRE}

C'est en effet probablement la première fois dans l.' histoire de la traduction professionnelle qu'un prix national a été décerné à des traducteurs non littéraires. Lancé par le groupe finlandais Traduct Oy spécialisé dans la communication internationale d'entreprise, le prix Traduct a ainsi été remis en octobre 1991 aux réalisateurs de trois projets: un ensemble de traducteurs pour leur traduction de logiciels anglais / finnois, une traductrice pour ses traductions français / finnois de plaquettes publicitaires d'un fabricant de skis et une étudiante pour son mémoire de maîtrise traitant du rapport entre texte et image dans les plaquettes publicitaires d'entreprises finlandaises et allemandes. Le jury chargé d'évaluer les travaux était composé de 6 membres: deux représentants du monde des affaires, deux enseignants d'instituts universitaires de traduction et deux traducteurs professionnels. Ce qui ajoute encore à l'originalité de ce prix, d'un montant de 10000 marks finlandais (environ 2000 dollars américains), c'est que les critères d'évaluation des travaux ne portaient pas uniquement sur le produit fini mais également sur son processus de fabrication, chaque projet devant être accompagné de commentaires décrivant les différentes phases du travail.

Le prix Traduct devrait dans un avenir proche passer sous la responsabilité de l'Association pour la promotion de la communication d'entreprise, ELVIRA, fondée à Turku (Finlande), également en 1991.

Dans un monde qui change, la traduction n'a pas encore dit son dernier mot.

YVES GAMBIER 